\title{
Immune complement activation is attenuated by surface nanotopography
}

This article was published in the following Dove Press journal:

International Journal of Nanomedicine

28 October 201I

Number of times this article has been viewed

\author{
Mats Hulander' \\ Anders Lundgren' \\ Mattias Berglin' \\ Mattias Ohrlander ${ }^{2}$ \\ Jukka Lausmaa ${ }^{3,4}$ \\ Hans Elwing' \\ 'Department of Cell and Molecular \\ Biology/Interface Biophysics, \\ University of Gothenburg, \\ Medicinaregatan 9E, Gothenburg, \\ ${ }^{2}$ Bactiguard AB, Stockholm, \\ ${ }^{3} \mathrm{SP}$ Technical Research Institute, \\ Boras, ${ }^{4}$ Biomatcell, The Sahlgrenska \\ Academy, University of Gothenburg, \\ Gothenburg, Sweden
}

\begin{abstract}
The immune complement (IC) is a cell-free protein cascade system, and the first part of the innate immune system to recognize foreign objects that enter the body. Elevated activation of the system from, for example, biomaterials or medical devices can result in both local and systemic adverse effects and eventually loss of function or rejection of the biomaterial. Here, the researchers have studied the effect of surface nanotopography on the activation of the IC system. By a simple nonlithographic process, gold nanoparticles with an average size of $58 \mathrm{~nm}$ were immobilized on a smooth gold substrate, creating surfaces where a nanostructure is introduced without changing the surface chemistry. The activation of the IC on smooth and nanostructured surfaces was viewed with fluorescence microscopy and quantified with quartz crystal microbalance with dissipation monitoring in human serum. Additionally, the ability of pre-adsorbed human immunoglobulin $\mathrm{G}$ (IgG) (a potent activator of the IC) to activate the IC after a change in surface hydrophobicity was studied. It was found that the activation of the IC was significantly attenuated on nanostructured surfaces with nearly a $50 \%$ reduction, even after pre-adsorption with IgG. An increase in surface hydrophobicity blunted this effect. The possible role of the curvature of the nanoparticles for the orientation of adsorbed IgG molecules, and how this can affect the subsequent activation of the IC, are discussed. The present findings are important for further understanding of how surface nanotopography affects complex protein adsorption, and for the future development of biomaterials and blood-contacting devices.
\end{abstract}

Keywords: nanostructure, protein adsorption, gold nanoparticles, QCM-D, IgG, innate immunity

\section{Introduction}

Surface nanotopography has recently been shown to influence events such as cell adhesion, cell viability, and tissue integration. ${ }^{1,2}$ These findings are expected to greatly influence the development of the next generation of biomaterials. ${ }^{3-5}$ Although the adsorption of proteins to biomaterial surfaces is considered important for cell response, fundamental knowledge of how nanostructured surfaces affect this event is still insufficient.

A general conception in biomaterials research is that one of the first events to occur when an implant or medical device encounters body fluids is the rapid adsorption of various plasma proteins onto the surface of the material. ${ }^{6-8}$ Among these are the proteins involved in the immune complement (IC) system. The IC system is part of the innate immune system, and one of its main functions is to act as a first line of defense against foreign objects, and is therefore highly important in the context of biomaterial and implant development. ${ }^{9,10}$
Correspondence: Mats Hulander Department of Cell and Molecular Biology/interface Biophysics, University of Gothenburg, Medicinaregatan 9E, SE-41390

Gothenburg, Sweden

$\mathrm{Tel}+463$ I 7862584

Fax +46317862599

Email mats.hulander@cmb.gu.se 
The adsorption of plasma proteins to nanoparticles has recently been subject to increased research, largely due to their potential as carriers of pharmaceuticals for targeted drug delivery or as adjuvants in vaccines. ${ }^{11,12}$ When nanoparticles in suspension are exposed to plasma or serum, the protein composition as well as the conformation of the adsorbed proteins is subject to changes which may have implications for a physiological response. ${ }^{12-14}$ However, on nanostructured surfaces, most studies so far have been carried out in singleprotein solutions, and the knowledge of how complex protein solutions such as serum or plasma interact with the surface is therefore limited.

Recently the authors of this paper have been studying different aspects of blood compatibility on a clinically used biomaterial coating comprised of nanosized particles of the noble metals gold $(\mathrm{Au})$, silver $(\mathrm{Ag})$, and palladium $(\mathrm{Pd}){ }^{15}$ They found that none of the individual metals in the coating could alone explain the low response in IC activation and thrombin/antithrombin complex formation found in their experiments. Based on this, the possibility that the nanostructure itself could have an effect on these events cannot be ignored.

The study of how nanotopography influence protein adsorption and cell adhesion has been considered difficult, since the introduction of a nanostructure on a surface often is associated with a change in surface chemistry. ${ }^{16}$ This present paper presents a solution to this problem using a simple selfassembly procedure (briefly overviewed in Figure 1) where gold nanoparticles are immobilized on a gold substrate and sintered onto the surface by a following washing step. The particles used for surface preparation in the present study are in a size range that has previously been reported to affect adsorption of plasma proteins. ${ }^{6,14}$

The IC is comprised of more than 20 different proteins including activation and inhibition factors revolving around the central complement factor $3(\mathrm{C} 3)$. The activation of the

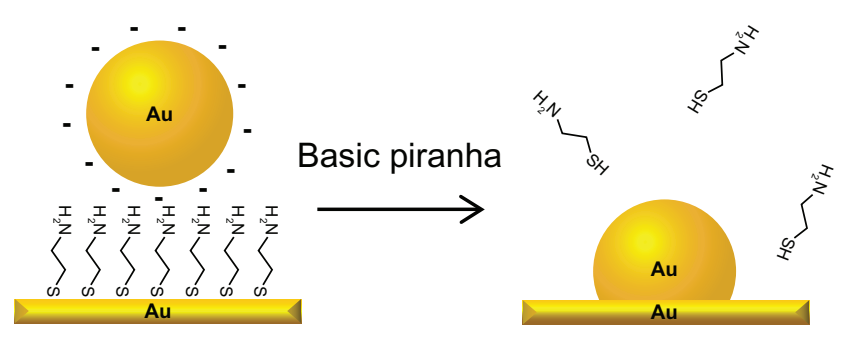

Figure I Schematic illustration of the fabrication process of the nanostructured gold surface: citrate protected gold nanoparticles are electrostatically immobilized to a self-assembled monolayer of cysteamine. After washing in basic piranha solution, the particles are integrated with the gold substrate and the cysteamine is desorbed, leaving a clean gold surface. complement system on biomaterial surfaces can be triggered via the classical or alternative pathway. ${ }^{17}$ The classical pathway is activated when the complement protein $\mathrm{C} 1$ binds to immunoglobulin $\mathrm{G}$ ( $\mathrm{IgG}$ ) molecules adsorbed on a surface. The alternative pathway is independent of $\mathrm{C} 1$ activation through antibodies and is instead triggered through the spontaneous hydrolysis of $\mathrm{C} 3$ to $\mathrm{C} 3 \mathrm{~b}$. It then proceeds, as the reactive thioester part of $\mathrm{C} 3 \mathrm{~b}$ binds to a surface or to proteins adsorbed on the surface. ${ }^{18}$ Both pathways generate the surface-bound $\mathrm{C} 3$ and $\mathrm{C} 5$ convertases. The $\mathrm{C} 3$ convertase catalyzes cleavage of $\mathrm{C} 3$ into $\mathrm{C} 3 \mathrm{~b}$ and the soluble peptide $\mathrm{C} 3 \mathrm{a}$, and the $\mathrm{C} 5$ convertase cleaves $\mathrm{C} 5$ to produce $\mathrm{C} 5 \mathrm{~b}$ and a soluble $\mathrm{C} 5 \mathrm{a}$ peptide. Both $\mathrm{C} 3 \mathrm{a}$ and $\mathrm{C} 5 \mathrm{a}$ enhance the inflammatory response through stimulation of mast cells and by recruiting macrophages to the complement activating site. ${ }^{19}$ The authors of this present paper have previously shown that surface-bound complement factor $\mathrm{C} 3 \mathrm{~b}$ can be measured and used to quantify activation of the IC. ${ }^{20,21}$

In the present study, fluorescence microscopy and quartz crystal microbalance with dissipation monitoring (QCM-D) was used to study the effects of nanotopography on the activation of the IC system in human serum. Additionally studied was the ability of adsorbed human IgG (a very potent activator of the IC) to activate the IC cascade on the surfaces, and how an increase in hydrophobicity of the nanostructured surfaces affected this ability.

\section{Material and methods Nanoparticle synthesis}

Gold nanoparticles were synthesized through the reduction of $\mathrm{Au}^{3+}$ ions to $\mathrm{Au}^{0}$ by citrate, using a modified version of a protocol described by Kimling et al. ${ }^{22}$ In brief, $100 \mathrm{~mL}$ of $1.5 \mathrm{mM}$ solution of gold salt was prepared by dissolving $\mathrm{HAuCl}_{4}$ (Sigma, St Louis, MO) in ultra-pure water $(18.2 \mathrm{M} \Omega \mathrm{cm})$. The solution was heated to $60^{\circ} \mathrm{C}$ and stirred vigorously, and $4 \mathrm{~mL}$ of sodium citrate $(1 \% \mathrm{w} / \mathrm{v})$ was then added as the reducing agent. The reaction was stopped after 1 hour, and the solution was diluted 1:2 with $10 \mathrm{mM}$ sodium citrate buffer at $\mathrm{pH}$ 4.0. This "stock" solution was then stored at room temperature until use (weeks).

\section{Surface preparation}

Gold substrates were purchased from Litcon AB (Gothenburg, Sweden). The substrates were prepared on $10 \mathrm{~mm} \times 10 \mathrm{~mm} \times 0.5 \mathrm{~mm}$ silica wafers by RF (radio frequency) sputtering of $150 \mathrm{~nm}$ gold on a supporting layer of $10 \mathrm{~nm}$ of titanium. The mean surface roughness (Rms) of the gold substrates was $0.9 \mathrm{~nm}$ according to atomic force 
microscopy measurements from the manufacturer. Standard gold QCM-D sensor crystals with an Rms $<3 \mathrm{~nm}$ according to the manufacturer, were purchased from Q-Sense (Gothenburg, Sweden). All surfaces were washed for 10 minutes at $80^{\circ} \mathrm{C}$ in a basic piranha solution containing 5:1:1 Milli-Q ${ }^{\circledR}$ (Millipore, Bedford, MA) water, $\mathrm{NH}_{3}(24 \%)$ and $\mathrm{H}_{2} \mathrm{O}_{2}(30 \%)$, washed in excess of Milli-Q water, and dried in gaseous $\mathrm{N}_{2}$. Surfaces to be deposited with gold nanoparticles were immersed in $20 \mathrm{mM}$ of cysteamine (Fluka, Buchs, Switzerland) dissolved in $99.5 \%$ ethanol, and incubated overnight to establish a self-assembled monolayer (SAM). After incubation, the surfaces were washed three times in $99.5 \%$ ethanol and an additional three times in Milli-Q water, and used immediately for particle immobilization.

Hydrophobic surfaces were created by incubation of the gold substrates directly after the washing procedure in $10 \mu \mathrm{M}$ 1-propane-thiol in $99.5 \%$ ethanol overnight.

\section{Immobilization of gold nanoparticles}

The stock solution of nanoparticles was centrifuged at $2900 \times g$ for 30 minutes, and the pellet was saved and resuspended in $10 \mathrm{mM}$ sodium citrate buffer. In total, the stock solution was concentrated 2:1. The concentrated particle solution was then incubated on the cysteamine-modified gold surfaces (see above) overnight. The surfaces were washed for 15 minutes at $70^{\circ} \mathrm{C}$ in basic piranha solution to sinter the particles to the surface and to wash away any residue of cysteamine, and used immediately for the experiments.

Surfaces to be used for the fluorescent detection of IC activation were gently scratched in a lengthwise manner with a syringe needle, creating thin lines (approximately $50 \mu \mathrm{m}$ wide) on the surface where the nanoparticles were removed (see Figure 2). In this way, both smooth and nanostructured areas could be housed on the same sample and could thus easily be compared in a single image. The syringe needle was mounted in a spring loaded fashion to ensure that a constant force was applied to the needle along the whole scratch. The surfaces were then washed in basic piranha for 15 minutes before use.

\section{Surface characterization}

The surfaces were viewed through a Zeiss 982 Gemini $^{\circledR}$ (Zeiss, Oberkochen, Germany) scanning electron microscope (SEM) operating at $10 \mathrm{kV}$ in secondary electron mode, using the in-lens detector. The average particle size and surface coverage was then determined using the image analysis software ImageJ (National Institutes of Health, Bethesda, MD) under the assumption that all particles were spherical.

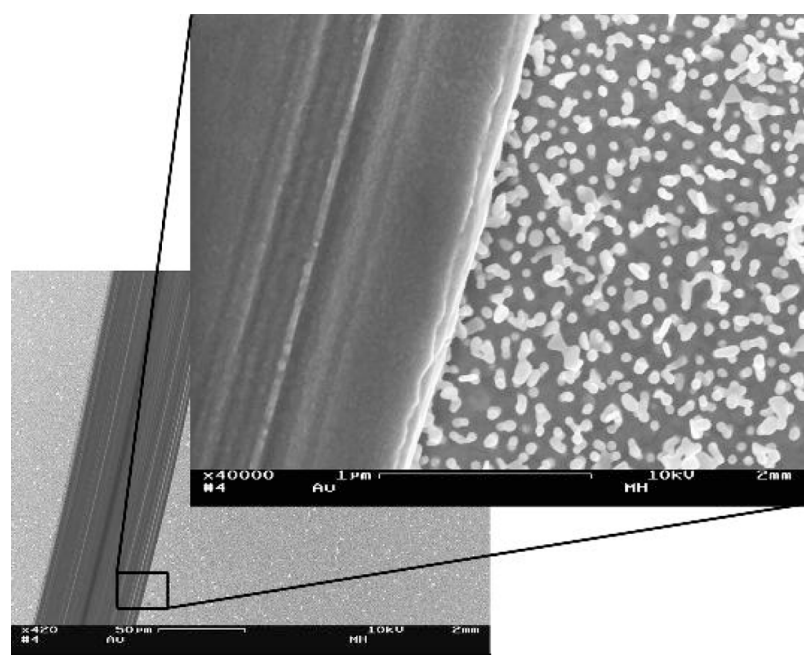

Figure 2 Scanning electron microscopy images showing a smooth area on a nanostructured gold surface, created by scratching away the particles with a syringe needle. The dark line represents the smooth area. The difference in surface roughness is clearly seen in the magnified inset.

To estimate the effect of the introduced nanostructure on the surface area available for protein binding, the surface capacitance was measured before and after modification with nanoparticles. The capacitance was measured using a dedicated instrument ${ }^{23}$ (Layerlab AB, Gothenburg, Sweden) using gold electrodes provided by the instrument manufacturer. For a bare gold electrode in salt solution, the capacitance depends on the thickness of the electrical double layer outside the electrode. For the physiological buffer used in this study, the double layer is $<1 \mathrm{~nm}$. Since the capacitance depends linearly on the electrode area, the small extension of the double layer will give capacitance values reflecting the real surface area of the nanostructured surfaces. ${ }^{24}$

Static contact angles were measured according to the sessile drop technique by adding a $10 \mu \mathrm{L}$ ultra-pure $(18.2 \mathrm{M} \Omega \mathrm{cm})$ water droplet to the surface, measuring the diameter and reading the contact angle in the table provided by Dahlgren and Sundquist. ${ }^{25}$

The surface chemical composition of smooth gold substrates and surfaces with immobilized nanoparticles was analyzed with X-ray photoemission spectroscopy (XPS) and time-of-flight secondary ion mass spectrometry (ToF-SIMS).

XPS survey spectra and high resolution spectra of selected peaks were measured on areas of $\sim 1 \mathrm{~mm}^{2}$, using a PHI 5500 instrument (Physical Electronics, Eden Prairie, $\mathrm{MN})$. Monochromatized Al-K $\alpha$ radiation (1486.6 eV) was used at a source power of $350 \mathrm{~W}$. Survey and high resolution spectra were acquired with a pass energy of $93.9 \mathrm{eV}$ and $23.5 \mathrm{eV}$, respectively. The take-off angle was $45^{\circ}$ in all cases. Quantification of relative concentrations (atom \%) were 
done with the software of the instrument, using a Tougaard background and tabulated sensitivity factors.

ToF-SIMS measurements were done with a ToF-SIMS IV instrument (ION-TOF GmbH, Münster, Germany), equipped with a bi-cluster primary ion source. Spectra of positive and negative secondary ions were measured from areas of $500 \mu \mathrm{m} \times 500 \mu \mathrm{m}$, using $25 \mathrm{keV} \mathrm{Bi}_{3}{ }^{+}$primary ions at an average beam current of around $0.1 \mathrm{pA}$ and instrument settings for high mass resolution (m/ $\mathrm{m}(\mathrm{FWHM})$ around 6000 at m/z 28). Acquisition times were kept below 200 seconds, ensuring that the spectra represented surfaces that were essentially undamaged by the primary ion beam.

\section{Blood products}

Fresh whole blood from eight healthy donors was a kind gift from Sahlgrenska University Hospital, Gothenburg, Sweden. The blood was left to clot at room temperature for 2 hours and then centrifuged at $500 \times g$. The supernatant serum was collected, pooled, and stored at $-70^{\circ} \mathrm{C}$ prior to the measurements.

\section{The QCM-D technique}

The quartz crystal microbalance technique is an acoustic method based on the piezo-electric properties of the quartz crystal. ${ }^{26}$ The technique is described in detail by Rodahl et al. ${ }^{27}$ Briefly, the resonance frequency of a sensor quartz crystal is monitored over time. Mass adsorbed onto the sensor results in a decrease in the resonance frequency $(\Delta f)$. The decrease is proportional to the adsorbed mass, which can be calculated by the Sauerbrey equation below:

$$
\Delta M=-C \frac{\Delta f}{n}
$$

where $M$ is the mass in $\mathrm{ng} / \mathrm{cm}^{2}, C$ is the mass sensitivity constant (17.7 $\mathrm{ng} \mathrm{cm}^{-2} \mathrm{~Hz}^{-1}$, for a $5 \mathrm{MHz}$ sensor crystal), and $n$ the overtone number $1,3, \ldots n$. The Sauerbrey equation is typically valid for the modeling of adsorbed homogenous layers and when $\Delta f$ values, normalized against their respective overtone, do not show large spreading. In this present experiment, the variation of the $\Delta f$ values for the different overtones was in the order of $10 \%$ or less. The use of QCM-D to study protein adsorption on nanostructured surfaces have previously been carried out by Lord et $\mathrm{al}^{28}$ and Malmstrom et al. ${ }^{29}$

\section{Fluorescent evaluation of IC activation}

The nanostructured surfaces carrying a scratch (see "Immobilization of gold nanoparticles") where the particles were removed were incubated with pooled human serum diluted $1: 5$ in veronal buffered saline containing $0.15 \mathrm{mM} \mathrm{CaCl}_{2}$ and $0.5 \mathrm{mM} \mathrm{MgCl}_{2}\left(\mathrm{VBS}^{2+}\right)$ for 20 minutes at room temperature. The surfaces were then rinsed with $\mathrm{VBS}^{2+}$ for 5 minutes, incubated with $380 \mu \mathrm{g} / \mathrm{mL}$ fluorescein isothiocyanate (FITC)-labeled rabbit antihuman C3c antibodies (Sigma) for 20 minutes, and finally rinsed with $\mathrm{VBS}^{2+}$ buffer for 5 minutes. Negative controls were performed in the same manner, but with the use of heat-inactivated serum $\left(56^{\circ} \mathrm{C}\right.$ for 30 minutes). The fluorescence of bound antibodies was then evaluated using a Leica DM-RXA fluorescence microscope (Leica Microsystems, Wetzlar, Germany) at 400× magnification with a FITC filter mounted, with the camera working in manual mode using the same exposure time and aperture for all images.

\section{QCM-D measurements of IC activation}

The IC activation was measured on standard QCM-D gold sensor crystals (QSX-301, Q-Sense) with or without immobilized gold nanoparticles. Pooled human serum was diluted 1:5 in veronal buffer saline containing $\mathrm{VBS}^{2+}$. The adsorption of serum proteins was then monitored for 20 minutes in the QCM-D at the third overtone $(15 \mathrm{MHz})$. A 5-minute rinse with buffer solution was then performed to wash away any unbound proteins. To detect complement $\mathrm{C} 3$ proteins on the surface, rabbit antihuman $\mathrm{C} 3 \mathrm{c}$ antibodies was subsequently introduced and incubated for 20 minutes at a concentration of $200 \mu \mathrm{g} / \mathrm{mL}$. A final rinse with buffer was then performed for 5 minutes to wash away any unbound antibodies. Positive controls and pre-adsorption studies with IgG were done by preadsorption on the surfaces of human $\mathrm{IgG}$ for 20 minutes at a concentration of $100 \mu \mathrm{g} / \mathrm{mL}$. Negative controls were performed in the same manner, but with the use of heatinactivated serum $\left(56^{\circ} \mathrm{C}\right.$ for 30 minutes $)$. To evaluate any contribution of the cysteamine SAM, an additional control experiment with cysteamine-coated smooth gold surfaces was performed. All measurements were performed in a minimum of four replicates on a QCM-D model D300 (Q-Sense) operating in ambient room temperature $\left(22.0^{\circ} \mathrm{C} \pm 0.2^{\circ} \mathrm{C}\right)$.

\section{Data analysis}

All experiments were performed in a minimum of five replicates, and data were analyzed using one way analysis of variance and Cochran's test. Error bars in figures represent standard deviation from the mean. 


\section{Results}

\section{SEM evaluation of surface-bound gold nanoparticles}

SEM analysis was performed before and after the washing procedure with basic piranha. In the SEM depiction in Figure 3A, the gold nanoparticles are clearly visible against the smooth gold background. After washing, the particles were further immobilized and partly integrated with the background surface, as seen in Figure 3B. The average particle diameter was $58 \mathrm{~nm}$, and the surface coverage of particles was on average $36 \%$.

\section{Surface analysis}

The surface capacitance of the experimental surfaces was measured in order to estimate the surface area magnification caused by the nanostructure. Capacitance was measured directly after washing of the surfaces in basic piranha solution to minimize the influence of adsorbed species. The capacitance, normalized to the nominal electrode area, was determined to $30.4 \mu \mathrm{F} / \mathrm{cm}^{2}$ for the smooth surfaces, and to $58.8 \mu \mathrm{F} / \mathrm{cm}^{2}$ for the nanostructured surfaces. This indicates that the surface area increases approximately $93 \%$ by the introduction of the nanotopography.

Water contact angle, XPS, and TOF-SIMS analyses were performed to ensure that surface topography, not chemistry, was the only parameter that differed between the surfaces. The physical properties of the surfaces are summarized in Table 1. After washing of the surfaces in basic piranha all surfaces were highly hydrophilic, demonstrated by water contact angles less than $10^{\circ}$. After hydrophobization, the water contact angles on both smooth and nanostructured surfaces were increased to around $80^{\circ}$ (Table 1 ).

XPS spectra (Figure 4) of the smooth surfaces and the nanostructured gold surfaces were essentially identical and dominated by strong signals from $\mathrm{Au}$ and also showed weak

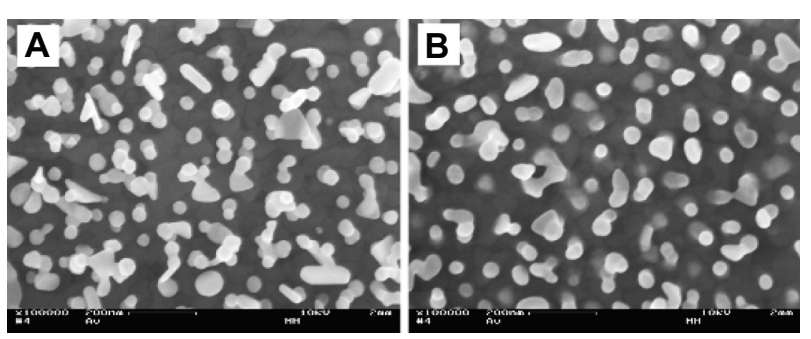

Figure 3 Scanning electron microscopy images of gold nanoparticles bound to the smooth gold background. (A) Particles bound to the surface by electrostatic interaction with a self-assembled monolayer of cysteamine. (B) After washing in basic piranha the particles are integrated with the background surface. Magnification: $100,000 \times$. signals from $\mathrm{C}$ and traces of $\mathrm{O}$ and $\mathrm{S}$. The chemical similarity between the surfaces was confirmed after calculation of the atomic concentrations of the elements detected in the XPS analysis (Table 1). ToF-SIMS analysis confirmed the chemical similarity between the surfaces, but also revealed some differences, mainly with regard to sulfate-related signals (ToFSIMS spectra are available in the Supplementary data).

\section{Fluorescent detection of the IC activation}

In the initial experiments, the activation of the IC on a smooth and a nanostructured surface were compared by the use of fluorescence microscopy. It was found that FITC-labeled anti-C3c antibodies bound to a significantly lower degree to serum proteins adsorbed on the immobilized gold nanoparticles, as seen in Figure 5. In the area where the nanoparticles were removed by scratching with a syringe needle (see Figure 2), antibodies bound to a higher extent, resulting in a very high intensity fluorescence, seen as a bright line in Figure 5A. The negative control (heat-inactivated serum) is seen in Figure 5B. All images were captured with the camera working in manual mode, using the same aperture and exposure time.

\section{QCM-D measurements of IC activation}

The IC activation was quantified with QCM-D as the amount of anti $\mathrm{C} 3 \mathrm{c}$ antibodies binding to a pre-adsorbed layer of human serum on the surfaces. Smooth hydrophilic surfaces adsorbed significantly less serum than the nanostructured hydrophilic surfaces, as seen in Figure 6A. The average mass of serum proteins adsorbed on the smooth surfaces was $1300 \mathrm{ng} / \mathrm{cm}^{2}$, and on the nanostructured surfaces, $2200 \mathrm{ng} / \mathrm{cm}^{2}$. As seen in Figure 6B, the IC was activated to a significantly higher degree in serum adsorbed to smooth hydrophilic surfaces than to nanostructured hydrophilic surfaces. On average, $1100 \mathrm{ng} / \mathrm{cm}^{2}$ of anti-C3c antibodies bound to the serum layer on the smooth gold surfaces, whereas $600 \mathrm{ng} / \mathrm{cm}^{2}$ bound to serum proteins adsorbed on the nanostructured surfaces.

\section{Activation of the IC system by pre-adsorbed $\lg G$}

In the attempt to provoke the activation of the IC by preadsorption of human IgG to the surfaces, it was found that IgG adsorbed to a significantly higher extent to hydrophilic nanostructured surfaces $\left(900 \mathrm{ng} / \mathrm{cm}^{2}\right)$ than to hydrophilic smooth surfaces $\left(600 \mathrm{ng} / \mathrm{cm}^{2}, P=0.01\right)$. Representative QCM-D graphs of the adsorption of IgG are available in the Supplementary data. 
Table I Physicochemical properties of smooth and nanostructured surfaces used in the experiments

\begin{tabular}{|c|c|c|c|c|c|c|c|c|}
\hline \multirow{2}{*}{$\begin{array}{l}\text { ESCA/XPS }(\%) \\
\text { (Relative sensitivity factor) }\end{array}$} & \multicolumn{4}{|c|}{ Smooth gold } & \multicolumn{4}{|c|}{ Nanogold } \\
\hline & $\begin{array}{l}\text { Cls } \\
30.7(0.3)\end{array}$ & $\begin{array}{l}\text { Ols } \\
5.2(0.7)\end{array}$ & $\begin{array}{l}\text { S2p } \\
1.6(0.7)\end{array}$ & $\begin{array}{l}\text { Au4f } \\
62.4(6.8)\end{array}$ & $\begin{array}{l}\text { Cls } \\
34.1(0.3)\end{array}$ & $\begin{array}{l}\text { Ols } \\
6.7(0.7)\end{array}$ & $\begin{array}{l}\text { S2p } \\
1.3(0.7)\end{array}$ & $\begin{array}{l}\text { Au4f } \\
57.9(6.8)\end{array}$ \\
\hline $\begin{array}{l}\text { Hydrophilic surfaces static water contact } \\
\text { angle (degrees) }\end{array}$ & \multicolumn{4}{|c|}{$<10 \pm 0$} & \multicolumn{4}{|c|}{$<10 \pm 0$} \\
\hline $\begin{array}{l}\text { Hydrophobic surfaces static water contact } \\
\text { angle (degrees) }\end{array}$ & \multicolumn{4}{|c|}{$80 \pm 10$} & \multicolumn{4}{|c|}{$78 \pm 9$} \\
\hline Particle surface coverage (\%) & \multicolumn{4}{|c|}{ - } & \multicolumn{4}{|c|}{$36 \pm 5$} \\
\hline Average particle diameter $(\mathrm{nm})$ & \multicolumn{4}{|c|}{-} & \multicolumn{4}{|c|}{$58 \pm 7$} \\
\hline Average surface roughness in $\mathrm{nm}(\mathrm{Rms})$ & \multicolumn{4}{|c|}{$0.9-3.0$} & \multicolumn{4}{|c|}{ - } \\
\hline
\end{tabular}

Abbreviations: ESCA, electron spectroscopy for chemical analysis; XPS, X-ray photoemission spectroscopy.

Shown in Figure 7 is the amount of $\operatorname{IgG}$ adsorbed to smooth (left group), and nanostructured (right group) hydrophilic surfaces, and the corresponding activation of the IC (binding of anti-C3c antibodies) that this amount of $\operatorname{IgG}$ induced. After incubation with serum, antibodies towards C3c bound to a significantly lower degree to the nanostructured surfaces $\left(700 \mathrm{ng} / \mathrm{cm}^{2}\right)$ when compared with the smooth ones $\left(1800 \mathrm{ng} / \mathrm{cm}^{2}\right)$.

In Figure 8, the amount of IgG adsorbed to hydrophobic smooth (left group), and nanostructured (right group) surfaces, and the corresponding activation of the IC is shown. When hydrophobized, no difference in IgG adsorption was seen between the surfaces $\left(900 \mathrm{ng} / \mathrm{cm}^{2}\right)$. A small, but not significant $(P=0.06)$, difference in anti-C3 antibody binding was found between the smooth $\left(2200 \mathrm{ng} / \mathrm{cm}^{2}\right)$ and nanostructured $\left(2500 \mathrm{ng} / \mathrm{cm}^{2}\right)$ hydrophobic surfaces. However, note the large increase in IgG-induced IC activation on the nanostructured surfaces when hydrophobized (compare right groups in Figures 7 and 8).

\section{Discussion}

A striking result in these experiments was the significantly reduced IC activation found on the nanostructured surfaces, apparent both in the fluorescence and QCM-D measurements (see Figures 5 and 6B respectively). Remarkably, although the amount of adsorbed serum increased $70 \%$ with the presence of the nanostructure, this increase did not result in a corresponding rise in IC activation. Instead, the activation

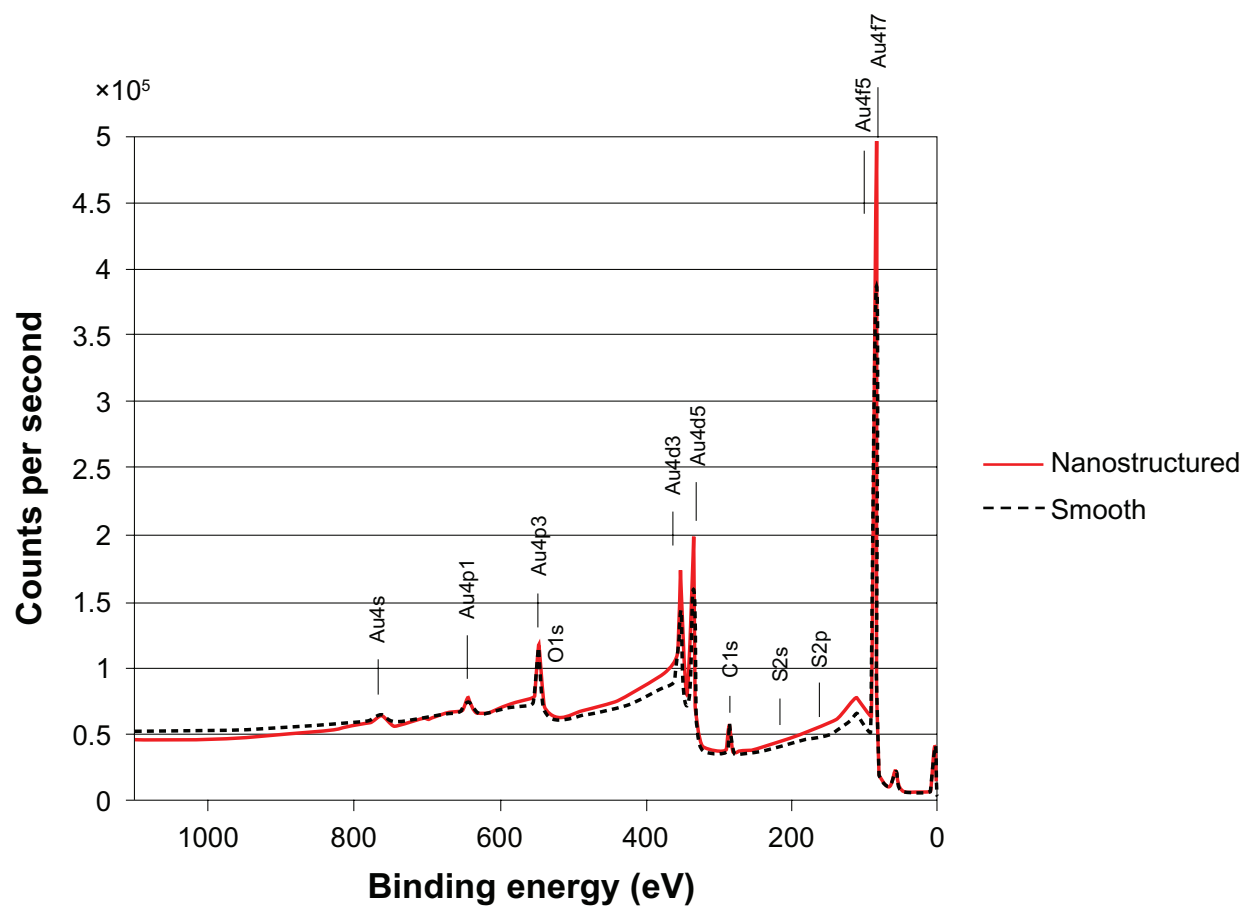

Figure 4 Overlay of X-ray photoemission spectroscopy survey spectra from nanostructured (solid line) and smooth (dotted line) surfaces, showing essentially similar chemical fingerprints. 

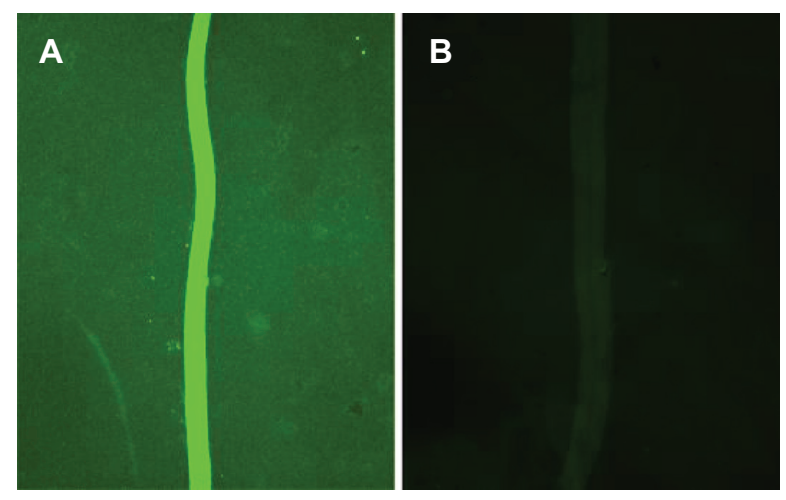

Figure 5 Fluorescence microscopy images of FITC-labeled antibodies binding to $\mathrm{C} 3 \mathrm{c}$ in serum adsorbed to the nanostructured surfaces visualized in Figure 3 . (A) The increased fluorescence from the smooth area of the surface is seen as a bright line. (B) Negative control using heat inactivated serum.

Abbreviation: FITC, fluorescein isothiocyanate. on the nanostructured surfaces was reduced by almost $50 \%$ (Figure 6A and B, respectively). From these experiments, it is therefore obvious that the mere introduction of nanoparticles on the surface induced changes to the adsorbing protein film. Pre-adsorption of $\operatorname{IgG}$ (a powerful activator of the IC) to the surfaces further enhanced this difference (see Figure 7). The observed differences in IC activation are therefore correlated to changes in IgG adsorption between smooth and nanostructured surfaces. The underlying reasons may be: (1) exclusion or higher exchange of IgG in serum proteins adsorbed to the nanostructured surfaces (Vroman effect); (2) increased structural stability of IgG molecules adsorbed to nanostructured surfaces; and (3) sterical restrictions imposed by the nanostructure on the binding of $\mathrm{IgG}$,
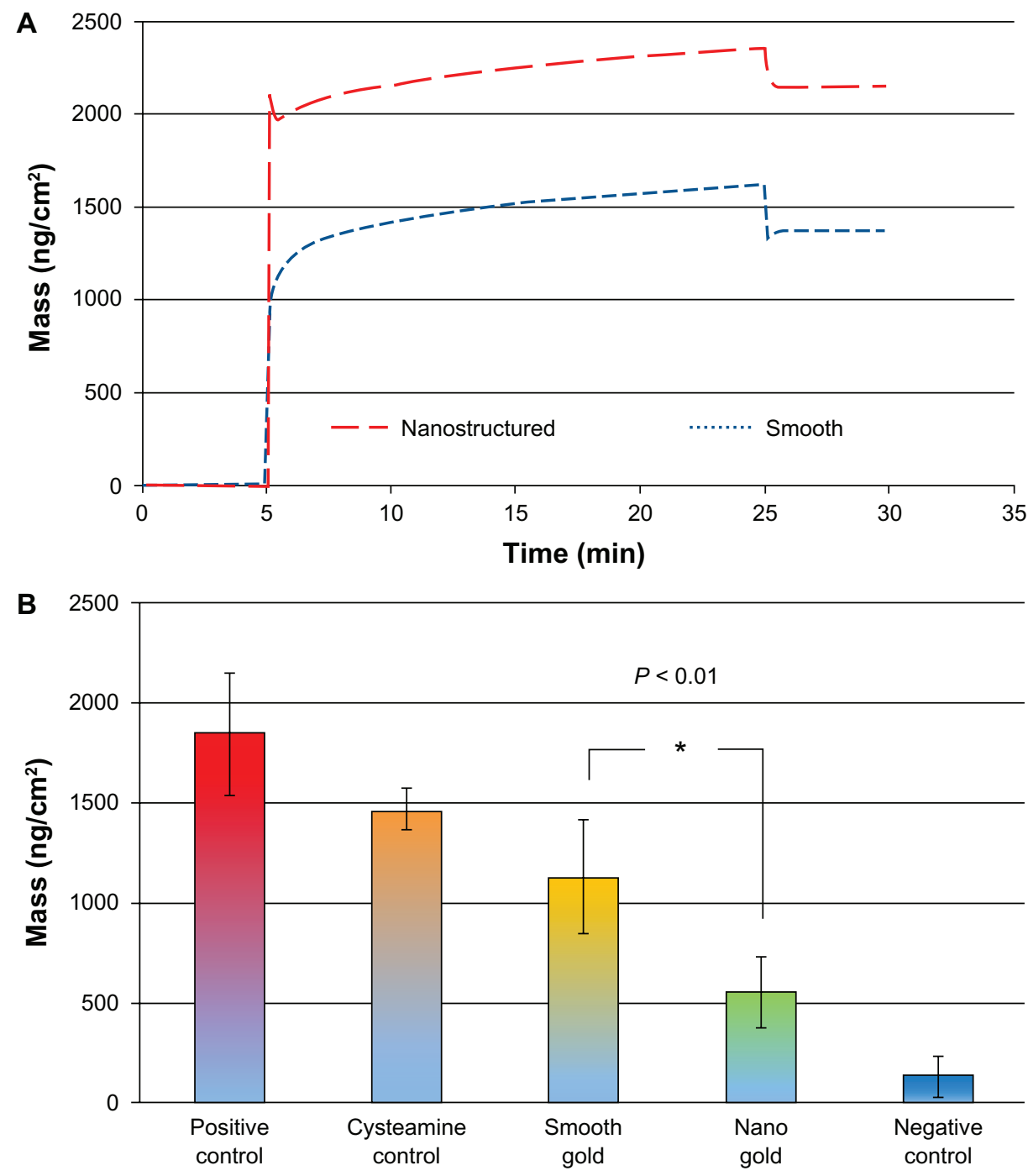

Figure 6 (A) QCM-D measurements of the mass adsorption of serum proteins on smooth and nanostructured surfaces. (B) Activation of the immune complement measured in QCM-D as the amount of binding anti-C3c antibodies to serum adsorbed on smooth or nanostructured gold surfaces. Positive controls with immunoglobulin $\mathrm{G}$ and cysteamine, and the negative control (heat-inactivated serum) are also shown.

Notes: Error bars represent standard deviations; $\mathrm{N} \geq 5$.

Abbreviation: QCM-D, quartz crystal microbalance with dissipation monitoring. 


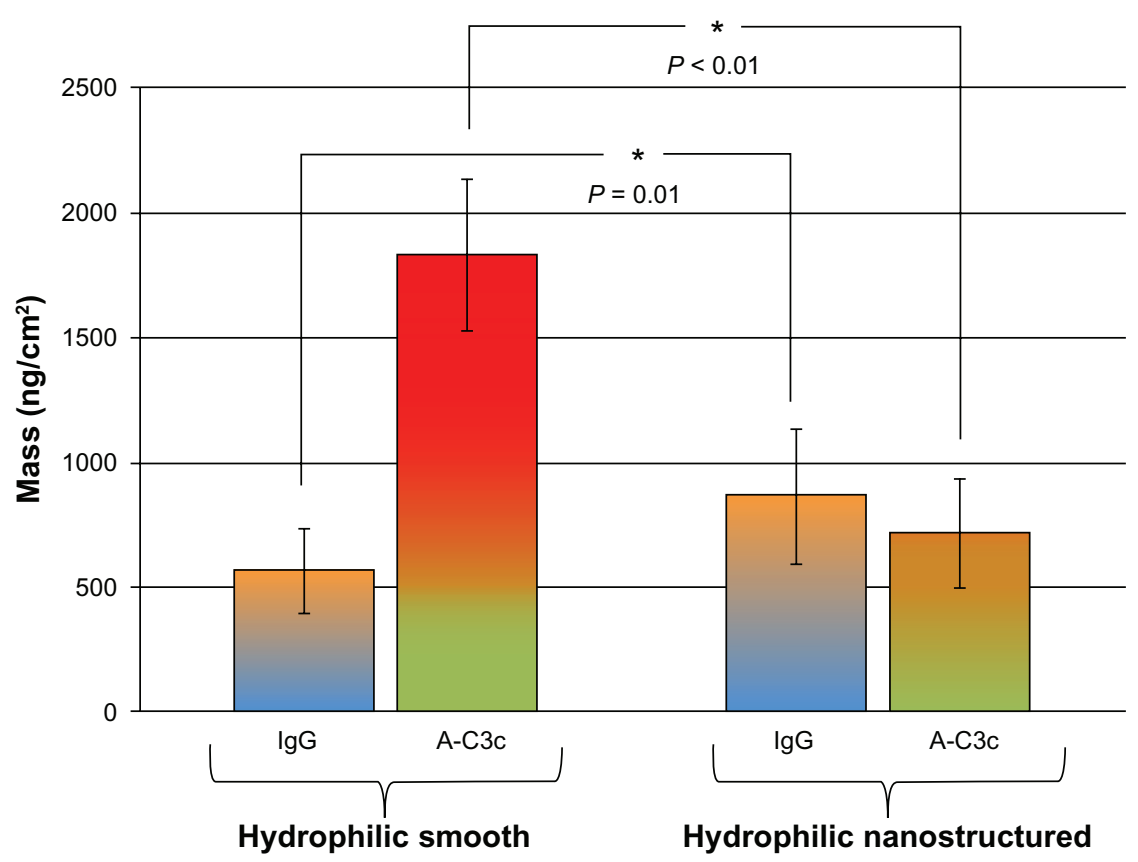

Figure 7 Adsorption of human IgG and the corresponding activation of the immune complement in human serum measured with QCM-D on hydrophilic surfaces. Smooth surfaces are shown to the left, and nanostructured surfaces to the right.

Notes: Error bars represent standard deviation; $N \geq 5$.

Abbreviations: IgG, immunoglobulin G; QCM-D, quartz crystal microbalance with dissipation monitoring.

affecting the interaction with complement proteins. Below, these different alternatives are discussed in the light of the results.

The classical pathway of the IC system is initiated when the head group of $\mathrm{C} 1 \mathrm{q}$ binds to a sufficient number of IgG molecules present on the surface. Upon binding, a change in the conformation of $\mathrm{C} 1 \mathrm{q}$ triggers the subsequent cascade events of the IC..$^{30,31}$ The introduction of nanostructures increased the amount of $\operatorname{IgG}$ by approximately $50 \%$ in these present experiments (Figure 7); hence the topography itself did not

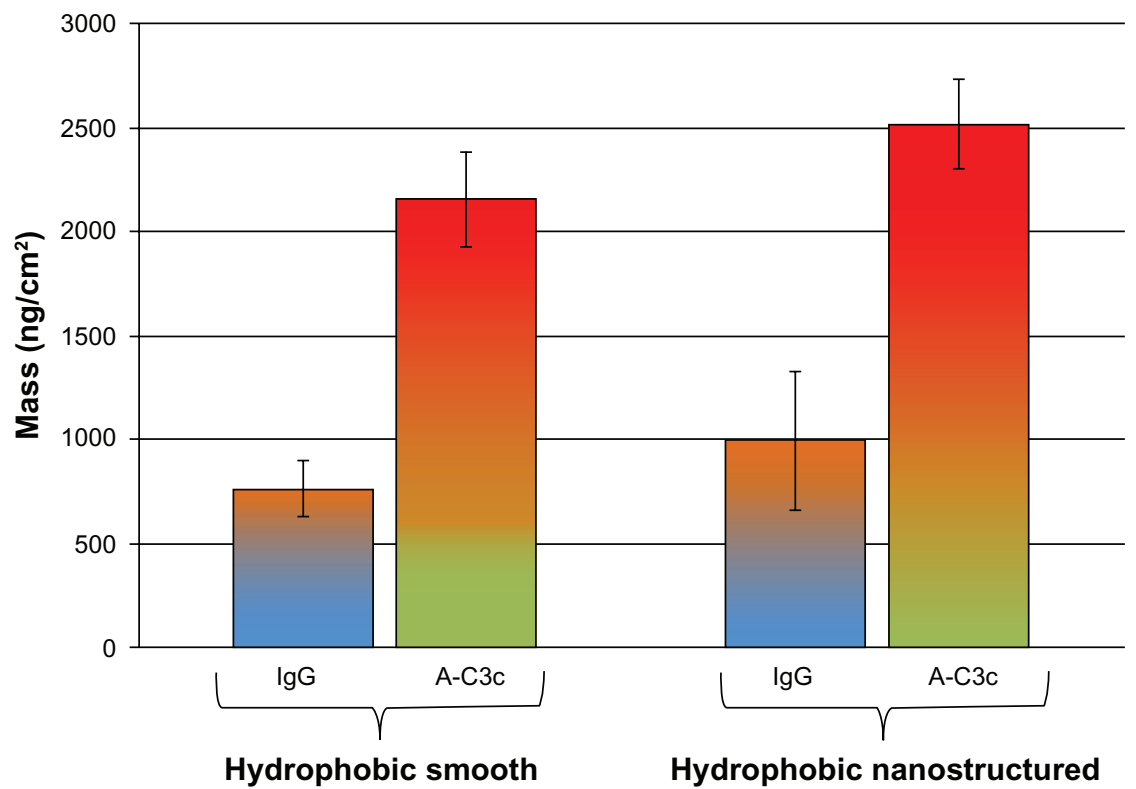

Figure 8 Adsorption of human IgG and the corresponding activation of the immune complement in human serum measured with QCM-D on hydrophobic surfaces. Smooth surfaces are shown to the left, and nanostructured surfaces to the right.

Note: Error bars represent standard deviation; $N \geq 5$.

Abbreviations: IgG, immunoglobulin G; QCM-D, quartz crystal microbalance with dissipation monitoring. 
seem to exclude adsorption of IgG molecules. Normalization with the real surface area, however, revealed that the surface density of IgG may be lower on the nanostructured surface. In a recent study by Lundqvist et al, ${ }^{14}$ the composition of the plasma protein corona on polystyrene nanoparticles was investigated; particles with a size of 50 and $100 \mathrm{~nm}$ and with three different surface chemistries (hydroxyl, amine, or unmodified) were used, and individual proteins in the corona was identified using mass spectrometry. After 1 hour of incubation in plasma, IgG was found on all particles, although to a lesser extent on the smaller $(50 \mathrm{~nm})$ hydrophilic particles. Comparing with Lundqvist et al's study, ${ }^{14}$ where IgG remained on the particles after 1 hour, the authors of this present paper find it likely that the pre-adsorbed IgG in this present study still remains after 20 minutes of subsequent serum adsorption. Therefore, the authors do not correlate the low activation of the IC on the nanostructured surfaces to removal or absence of IgG during serum adsorption. Earlier ellipsometric investigations of IgG and serum show that IgG is rapidly (within minutes) adsorbed on both hydrophilic and hydrophobic silicon surfaces. ${ }^{21}$ This is in accordance with the findings of this present study, where a near saturation of $\mathrm{IgG}$ is seen on all surfaces after 20 minutes of adsorption, regardless of surface energy (see QCM-D measurements in the Supplementary data). Any prolonged pre-adsorption of IgG to the surfaces would therefore most likely not change the outcome of these experiments.

It is generally considered that proteins undergo a certain amount of deformation or conformational change upon adsorption. These changes have previously been shown to increase with an increase in hydrophobicity of the surface for a number of proteins including $\operatorname{IgG}^{32,33}$ (see also the Supplementary data for detailed information on QCM-D measurements of IgG adsorption). An increase in IC activation by precoated IgG on hydrophobic surfaces has earlier been reported by Wettero et $\mathrm{al}^{34}$ and has been proposed to originate from surface-induced conformational changes of the IgG molecule. ${ }^{35}$ However, in the attempt to augment the activation of the IC by pre-adsorption of IgG, high activation was found on smooth surfaces regardless of their hydrophobicity (compare left groups in Figures 7 and 8). Intriguingly, when nanotopography was introduced on the surface, the activation was markedly restrained, as seen in Figure 7. This phenomenon was strongly affected by a change in hydrophobicity, resulting in a high activation when the nanostructured surface was hydrophobized (compare right groups in Figures 7 and 8). Since no differences in surface density of $\mathrm{IgG}$ were found between hydrophilic and hydrophobic nanostructured surfaces, the authors ascribe the low IC activation on the nanostructured surface to a combination of preserved nativity of the adsorbed IgG molecule and nanotopography. Based on this, the authors propose a mechanism below in which the nanotopography of hydrophilic surfaces is suggested to play a role for the orientation of adsorbed IgG molecules, thereby attenuating the activation of the IC.

The monomeric IgG molecule has a size of $14.5 \mathrm{~nm}$ (height) $\times 8.5 \mathrm{~nm}($ width $) \times 4 \mathrm{~nm}$ (thickness). ${ }^{36}$ The approximate "footprint" of the molecule will hence occupy an area of roughly $35 \mathrm{~nm}^{2}$. At random sequential adsorption ( $\sim 54 \%$ surface coverage), approximately $170 \mathrm{IgG}$ molecules would adsorb on the surface of a $60 \mathrm{~nm}$ spherical nanoparticle, a number most sufficient to activate the IC. However, when compared with a flat surface, the curvature of a particle will affect the distance between the adsorbed molecules, as illustrated in Figure 9. This effect naturally decreases with increasing particle size, and eventually the surface of the sphere will appear flat to the adsorbing protein. If the particle instead reaches a certain minimum size, it will be too small to affect the orientation of the protein, and the surface will again appear flat. Interestingly, in the aforementioned study by Lundqvist et al, ${ }^{14}$ although IgG fragments were found in the corona on all particles regardless of size or surface modification, the complement protein $\mathrm{C} 1 \mathrm{q}$ was not found on the smaller $(50 \mathrm{~nm})$ hydrophilic particles. This phenomenon was not observed on the unmodified (hydrophobic) particles, where $\mathrm{Clq}$ was found on particles of both size. In these present experiments, classical IC activation was markedly reduced on the nanostructured hydrophilic surface compared with the smooth ones, but not when the surfaces were made hydrophobic (Figures 7 and 8, respectively).

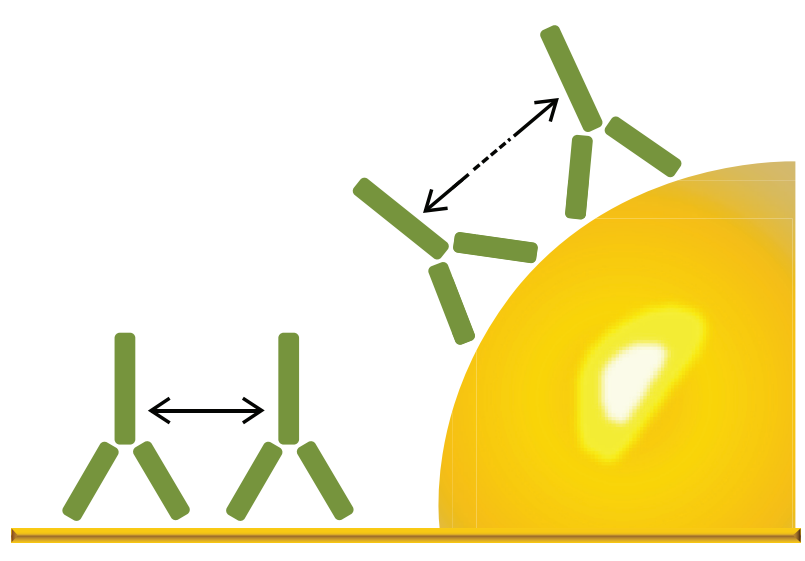

Figure 9 Illustration of how the curvature of a $60 \mathrm{~nm}$ particle affects the distance between adsorbed proteins. In this example, the distance between the $\mathrm{Clq}$ binding hinge region of immunoglobulin $\mathrm{G}$ molecules are clearly increased by the curvature. (Image drawn according to scale.) 
The structure of the IgG binding domain of $\mathrm{C} 1 \mathrm{q}$ consists of six globular heads that are equally distributed in a circle of approximately $20 \mathrm{~nm}$ in diameter. ${ }^{37}$ Thus, in order to activate $\mathrm{C} 1 \mathrm{q}$, the required number of $\mathrm{IgG}$ molecules must be present within this diameter. Crystallography of the IgG binding part of the $\mathrm{C} 1 \mathrm{q}$ head also suggests the important role of the relative orientation of the Fc and Fab regions of the IgG molecule for successful binding between $\mathrm{C} 1 \mathrm{q}$ and $\mathrm{IgG} .{ }^{38}$ The authors of this present paper suggest that the particles used in this present study and Lundqvist et al's study are in a required size range that will prevent a sufficiently large number of IgG molecules from adsorbing close enough, or in the required alignment on the surface to bind to the head groups of $\mathrm{C} 1 \mathrm{q}$. Also, when the particles/nanostructured surfaces are hydrophobized, a higher degree of denaturation of IgG is expected, and this effect therefore vanishes. This could explain the lack of $\mathrm{Clq}$ on the $50 \mathrm{~nm}$ hydrophilic particles (but not on the $100 \mathrm{~nm}$ ) in Lundqvist et al's study and the markedly reduced classical activation of the IC on the nanostructured surfaces in this present study.

To ensure that chemicals used in the fabrication of the nanostructured surfaces were effectively removed by the washing process, extensive surface chemistry analyses were carried out. The low $\left(<10^{\circ}\right)$ water contact angles found on both smooth and nanostructured surfaces ensured a clean surface and were strongly supported by the results from the surface sensitive (1-10 nm analytical depth) XPS analyses (Figure 4). If present, residues from cysteamine used in the immobilization of the gold nanoparticles would be detected as differences in sulfur or nitrogen signals in the XPS spectra. After washing in basic piranha, only $\sim 1.5$ atom $\%$ of sulfur was detected on the surfaces, and nitrogen signals were below the detection limit of the instrument. The even more sensitive ToF-SIMS analyses (see the Supplementary data) confirmed the overall similarities between the surfaces, but also confirmed the small difference in sulfur content seen in the XPS analyses (Table 1). However, these are minute differences in already very low amounts, and the authors of this paper therefore regard the surfaces as having the same surface chemistry.

Through the simple protocol provided here, nanostructured model surfaces with a defined surface chemistry can easily be produced in any conventional laboratory to a feasible cost. Due to the gold chemistry of the surfaces, thiolated molecules can be covalently bound to the surface to achieve a variety of functional surface chemistries. The authors believe that the use of these surfaces as model biomaterial surfaces can be a helpful tool in the understanding of how nanostructured biomaterials interact with proteins, cells, and tissue.

\section{Conclusion}

In this study, a simple and robust process was developed where nanostructured surfaces with defined surface chemistry can easily be fabricated. From these present experiments it can be concluded that the presence of surface-bound hydrophilic gold nanoparticles suppresses the activation of the IC system. The ability of human IgG to activate the IC system was also significantly reduced by the nanostructures of the surface. This effect was blunted by an increase in hydrophobicity.

\section{Acknowledgments}

The authors acknowledge Bactiguard AB for financial support, Per Borchardt at SP technical research institute for his excellence in TOF-SIMS, Urban Jelvestam for XPS measurements, and Julia Hedlund for her skills in electrochemical measurements. They also thank Kristina Nilsson Ekdahl and Pentti Tengvall for helpful discussions.

\section{Disclosure}

The authors report no conflicts of interest in this work.

\section{References}

1. Lipski AM, Pino CJ, Haselton FR, Chen IW, Shastri VP. The effect of silica nanoparticle-modified surfaces on cell morphology, cytoskeletal organization and function. Biomaterials. 2008;29(28):3836-3846.

2. Anselme K, Ploux L, Ponche A. Cell/material interfaces: influence of surface chemistry and surface topography on cell adhesion. JAdhesion Sci Technol. 2010;24(5):831-852.

3. Zhang LJ, Webster TJ. Nanotechnology and nanomaterials: promises for improved tissue regeneration. Nano Today. 2009;4(1):66-80.

4. Goldberg M, Langer R, Jia XQ. Nanostructured materials for applications in drug delivery and tissue engineering. J Biomater Sci Polym Ed. 2007;18(3):241-268.

5. Mitragotri S, Lahann J. Physical approaches to biomaterial design. Nat Mater. 2009;8(1):15-23.

6. Roach P, Farrar D, Perry CC. Interpretation of protein adsorption: surface-induced conformational changes. JAm Chem Soc. 2005;127(22): 8168-8173.

7. Tang L, Hu W. Molecular determinants of biocompatibility. Expert Rev Med Devices. 2005;2(4):493-500.

8. Wilson CJ, Clegg RE, Leavesley DI, Pearcy MJ. Mediation of biomaterial-cell interactions by adsorbed proteins: a review. Tissue Eng. 2005;11(1-2):1-18.

9. Nilsson B, Ekdahl KN, Mollnes TE, Lambris JD. The role of complement in biomaterial-induced inflammation. Mol Immunol. 2007;44(1-3): 82-94.

10. Remes A, Williams DF. Immune response in biocompatibility. Biomaterials. 1992;13(11):731-743.

11. Aggarwal P, Hall JB, McLeland CB, Dobrovolskaia MA, McNeil SE. Nanoparticle interaction with plasma proteins as it relates to particle biodistribution, biocompatibility and therapeutic efficacy. Adv Drug Deliv Rev. 2009;61(6):428-437. 
12. Karmali PP, Simberg D. Interactions of nanoparticles with plasma proteins: implication on clearance and toxicity of drug delivery systems. Expert Opin Drug Deliv. 2011;8(3):343-357.

13. Lynch I, Dawson KA. Protein-nanoparticle interactions. Nano Today. 2008;3(1-2):40-47.

14. Lundqvist M, Stigler J, Elia G, Lynch I, Cedervall T, Dawson KA. Nanoparticle size and surface properties determine the protein corona with possible implications for biological impacts. Proc Natl Acad Sci US A. 2008;105(38):14265-14270.

15. Hulander M, Hong J, Andersson M, et al. Blood interactions with noble metals: coagulation and immune complement activation. ACS Appl Mater Interfaces. 2009;1(5):1053-1062.

16. Jager M, Zilkens C, Zanger K, Krauspe R. Significance of nano- and microtopography for cell-surface interactions in orthopaedic implants J Biomed Biotechnol. 2007; Article ID: 69036.

17. Gorbet MB, Sefton MV. Biomaterial-associated thrombosis: roles of coagulation factors, complement, platelets and leukocytes. Biomaterials. 2004;25(26):5681-5703.

18. Andersson J, Ekdahl KN, Lambris JD, Nilsson B. Binding of C3 fragments on top of adsorbed plasma proteins during complement activation on a model biomaterial surface. Biomaterials. 2005;26(13): 1477-1485.

19. Franz S, Rammelt S, Scharnweber D, Simon JC. Immune response to implants - a review of the implications for the design of immunomodulatory biomaterials. Biomaterials. 2011;32(28):6692-6709.

20. Andersson M, Andersson J, Sellborn A, Berglin M, Nilsson B, Elwing H. Quartz crystal microbalance-with dissipation monitoring (QCM-D) for real time measurements of blood coagulation density and immune complement activation on artificial surfaces. Biosens Bioelectron. 2005;21(1):79-86.

21. Elwing H, Ivarsson B, Lundstrom I. Complement deposition from human sera on silicon surfaces studied insitu by ellipsometry - the influence of surface wettability. Eur J Biochem. 1986;156(2):359-365.

22. Kimling J, Maier M, Okenve B, Kotaidis V, Ballot H, Plech A. Turkevich method for gold nanoparticle synthesis revisited. J Phys Chem B. 2006;110(32):15700-15707.

23. Hedlund J, Lundgren A, Lundgren B, Elwing H. A new compact electrochemical method for analyzing complex protein films adsorbed on the surface of modified interdigitated gold electrodes. Sensors Actuators B Chem. 2009;142(2):494-501.

24. Bard AJ, Faulkner LR. Electrochemical Methods. 2nd ed. New York: John Wiley \& Sons Inc; 2001.

25. Dahlgren C, Sundquist T. Phagocytosis and hydrophobicity: a method of calculating contact angles based on the diameter of sessile drops. J Immunol Methods. 1981;40:171-179.
26. Sauerbrey G. Verwendung von Schwingquartzen zur Wägung dünner Schichten und Mikrowägung. The use of an oscillating quartz crystal for micro-weighing and weighing of thin films. Zeitschrift für Physik. 1959: 155(206-222). (German)

27. Rodahl M, Hook F, Krozer A, Brzezinski P, Kasemo B. Quartz-crystal microbalance setup for frequency and Q-factor measurements in gaseous and liquid environments. Rev Sci Instrum. 1995;66(7):3924-3930.

28. Lord MS, Cousins BG, Doherty PJ, et al. The effect of silica nanoparticulate coatings on serum protein adsorption and cellular response. Biomaterials. 2006;27(28):4856-4862.

29. Malmstrom J, Agheli H, Kingshott P, Sutherland DS. Viscoelastic Modeling of highly hydrated laminin layers at homogeneous and nanostructured surfaces: quantification of protein layer properties using QCM-D and SPR. Langmuir. 2007;23(19):9760-9768.

30. Kishore U, Kojouharova MS, Reid KBM. Recent progress in the understanding of the structure-function relationships of the globular head regions of C1q. Immunobiology. 2002;205(4-5):355-364.

31. Hwang HY, Duvall MR, Tomlinson S, Boackle RJ. Highly specific inhibition of C1q globular-head binding to human IgG: a novel approach to control and regulate the classical complement pathway using an engineered single chain antibody variable fragment. Mol Immunol. 2008;45(9):2570-2580.

32. Sivaraman B, Fears KP, Latour RA. Investigation of the effects of surface chemistry and solution concentration on the conformation of adsorbed proteins using an improved circular dichroism method. Langmuir. 2009;25(5):3050-3056.

33. Buijs J, Norde W. Changes in the secondary structure of adsorbed IgG and $\mathrm{F}\left(\mathrm{ab}^{\prime}\right)$, studied by FTIR spectroscopy. Langmuir. 1996; 12(6):1605-1613.

34. Wettero J, Askendal A, Bengtsson T, Tengvall P. On the binding of complement to solid artificial surfaces in vitro. Biomaterials. 2002;23(4):981-991.

35. Sellborn A, Andersson M, Hedlund J, Andersson J, Berglin M, Elwing H. Immune complement activation on polystyrene and silicon dioxide surfaces. Impact of reversible IgG adsorption. Mol Immunol. 2005;42(5):569-574.

36. Lee KB, Park SJ, Mirkin CA, Smith JC, Mrksich M. Protein nanoarrays generated by dip-pen nanolithography. Science. 2002;295(5560): 1702-1705.

37. Kilchherr E, Hofmann H, Steigemann W, Engel J. Structural model of the collagen-like region of $\mathrm{C} 1 \mathrm{q}$ comprising the kink region and the fibrelike packing of the 6 triple helices. J Mol Biol. 1985;186(2):403-415.

38. Gaboriaud C, Juanhuix J, Gruez A, et al. The crystal structure of the globular head of complement protein C1q provides a basis for its versatile recognition properties. J Biol Chem. 2003;278(47):46974-46982. 


\section{Supplementary data ToF-SIMS analyses}

To further investigate the chemical composition of the flat and nanostructured surfaces, time-of-flight secondary ion mass spectrometry (ToF-SIMS) was used. ToF-SIMS is an even more surface-sensitive chemical analysis technique than X-ray photoemission spectroscopy (XPS), with a probing depth of 1-3 nm. Being a high resolution mass spectrometric technique, ToF-SIMS also has the potential to provide more detailed and molecule-specific chemical information than XPS, via secondary ion peaks representing intact molecular ions or unique or characteristic fragment ions of the molecules present on the surface. For comparison, the scratched area of the nanostructured surfaces, and a cysteamine-coated surface which had not been subjected to the piranha washing step, was also analyzed.

The results of the analyses are shown in Supplementary Figure S1A and B, which show representative positive and negative ion spectra, respectively, from the four investigated types of surfaces. For clarity, each set of spectra is presented as two mass ranges, the left panels showing a mass-tocharge ratio $(\mathrm{m} / \mathrm{z})=9-200$ and the right panels showing $\mathrm{m} / \mathrm{z}=180-600$.

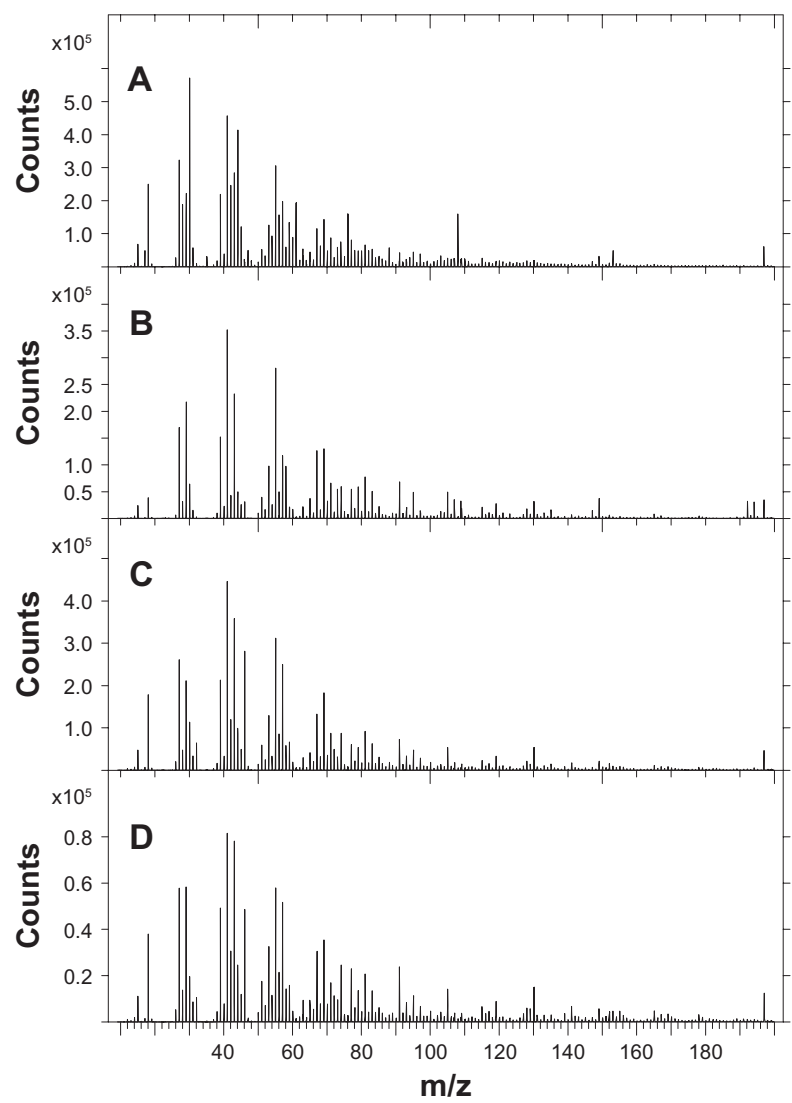

Positive spectra in the lower mass range show a similar overall appearance and are dominated by strong organic signals of the type $\mathrm{C}_{\mathrm{x}} \mathrm{H}_{\mathrm{y}}{ }^{+}$at odd mass numbers, with the exception for the cysteamine surface, which also has strong organic signals at even mass numbers, representing $\mathrm{C}_{\mathrm{x}} \mathrm{H}_{\mathrm{y}} \mathrm{N}$ species. The peak at $\mathrm{m} / \mathrm{z}=76$, which is only observed for the cysteamine sample, can be assigned to a deprotonated cysteamine molecular ion $(\mathrm{M}-\mathrm{H})^{+}$. The peaks from $\mathrm{C}_{\mathrm{x}} \mathrm{H}_{\mathrm{y}} \mathrm{N}$ species also appear at the nanostructured surface and the scratched surface, although at lower intensities. A clear peak from $\mathrm{NH}_{4}{ }^{+}$is observed at all surfaces, but with a lower intensity for the flat surface. The peak from gold is weak, but this is due to the fact that $\mathrm{Au}^{+}$has a low secondary ion yield. In the higher mass range, the spectra are dominated by species of the type $\mathrm{AuC}_{\mathrm{x}} \mathrm{H}_{\mathrm{y}}{ }^{+}$, and the gold trimer at $\mathrm{m} / \mathrm{z}=591$, which is characteristic for a gold surface. The cysteamine surface differs from those of the other surface, by the presence of a strong peak at $\mathrm{m} / \mathrm{z}=257$, which can be assigned to an $\mathrm{Au}$-cysteamine complex that has lost an amino group due to fragmentation by the primary ion beam. This peak is absent in the spectrum from the flat surface, and very weak for the nanostructured surface.

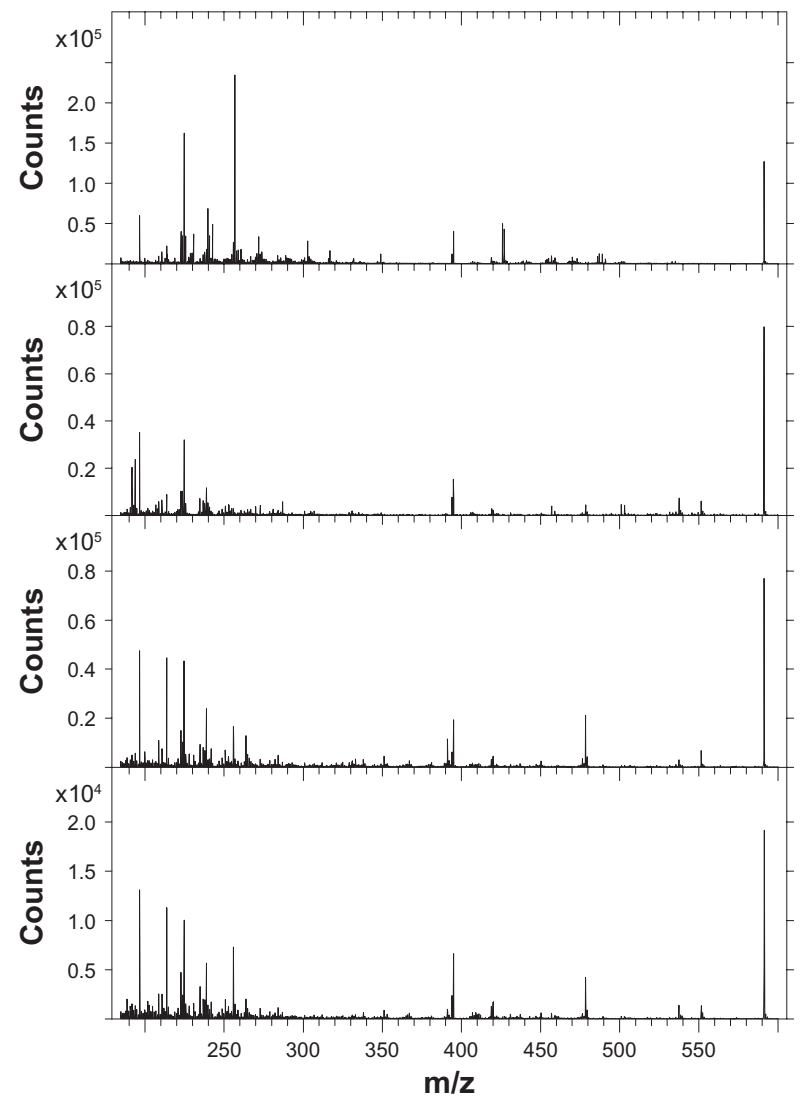

Figure SI Positive secondary ion mass spectra from (A) cysteamine, nonwashed gold surface, (B) flat gold surface, (C) nanostructured gold surface, and (D) scratched area on nanostructured surface. 
The negative spectra in the lower mass range for all surfaces show strong signals from $\mathrm{Au}$ and the gold trimer at $\mathrm{m} / \mathrm{z}=591$. In addition, all spectra show strong peaks at $\mathrm{m} / \mathrm{z}=26$ and 42, which can be assigned to $\mathrm{CN}$ and $\mathrm{CNO}$, respectively. For the cysteamine surface, the nanostructured surface, and the scratched area in the nanostructured surface, strong signals from sulfate species such as $\mathrm{SO}_{2}, \mathrm{SO}_{3}, \mathrm{SO}_{4}$, and $\mathrm{HSO}_{4}$ are observed, as well as an unidentified peak at $\mathrm{m} / \mathrm{z}=311$. These peaks are all very weak for the flat surface. The nanostructured surface and the scratched surface show some additional unidentified peaks at higher masses that are weak or not present for the flat surface.

Overall, the ToF-SIMS spectra thus show many similarities between the flat surface and the nanostructured surface. On the other hand, several spectral differences can be observed, most of which appear to be associated with sulfate species (in negative spectra) and nitrogen-containing organic species (in positive spectra), both of which presumably originate from the cysteamine pretreatment.

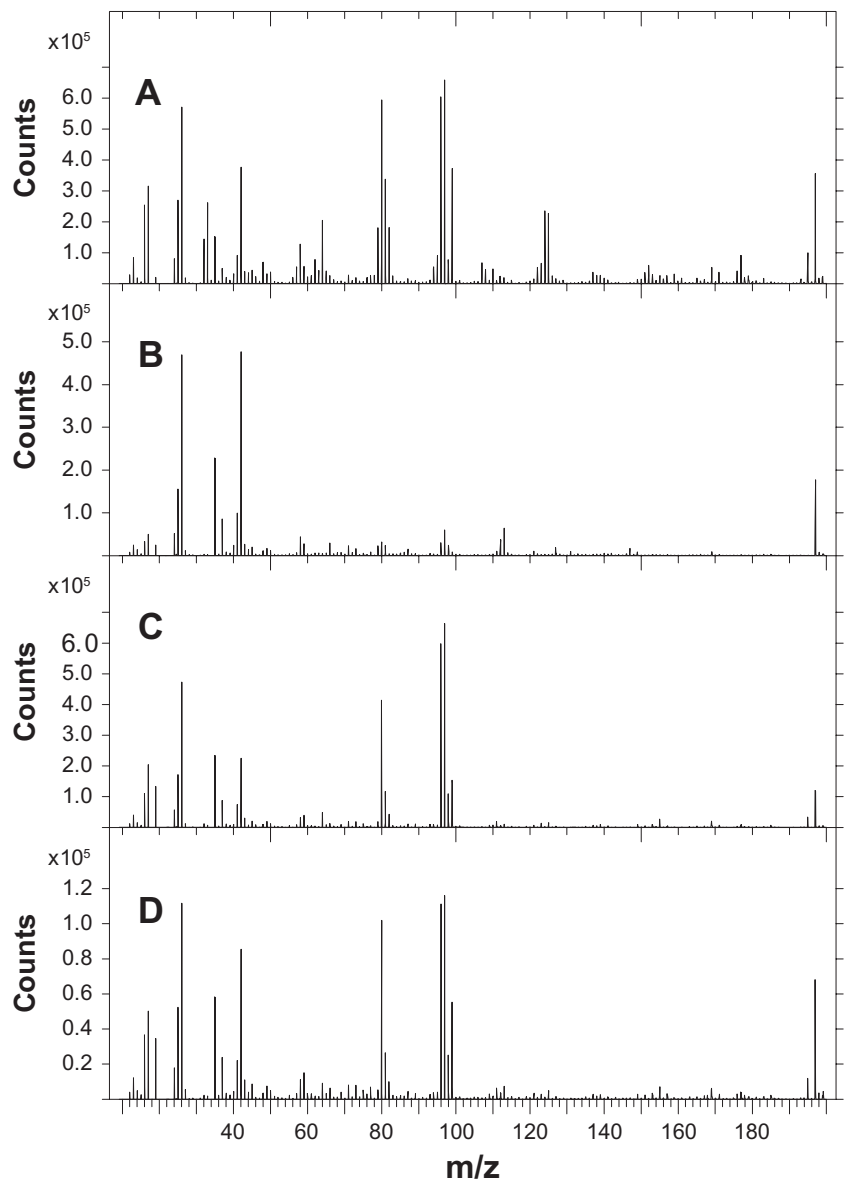

\section{Quartz crystal microbalance with dissipation monitoring (QCM-D) measurements of immunoglobulin $\mathrm{G}$ (lgG) adsorption}

In QCM-D, both mass and viscoelastic properties (dissipation) of an adsorbing protein can be measured in real time. A negative change in frequency is proportional to increased mass load on the surface. Dissipation is a dimensionless entity that describes the viscoelastic modulus of the adsorbed mass. Typically, a soft matter will give rise to a higher dissipation than a rigid one. A positive shift in dissipation indicates a higher loss of energy from the oscillating QCM-D crystal and is generally interpreted as loss of organized structure of the adsorbing layer. In Supplementary Figure S3, representative data from the adsorption of human IgG onto hydrophilic and hydrophobic smooth and nanostructured gold surfaces are presented. A higher shift in dissipation was observed on the hydrophobic surfaces, regardless of surface nanotopography, indicating a higher degree of denaturation of the protein.

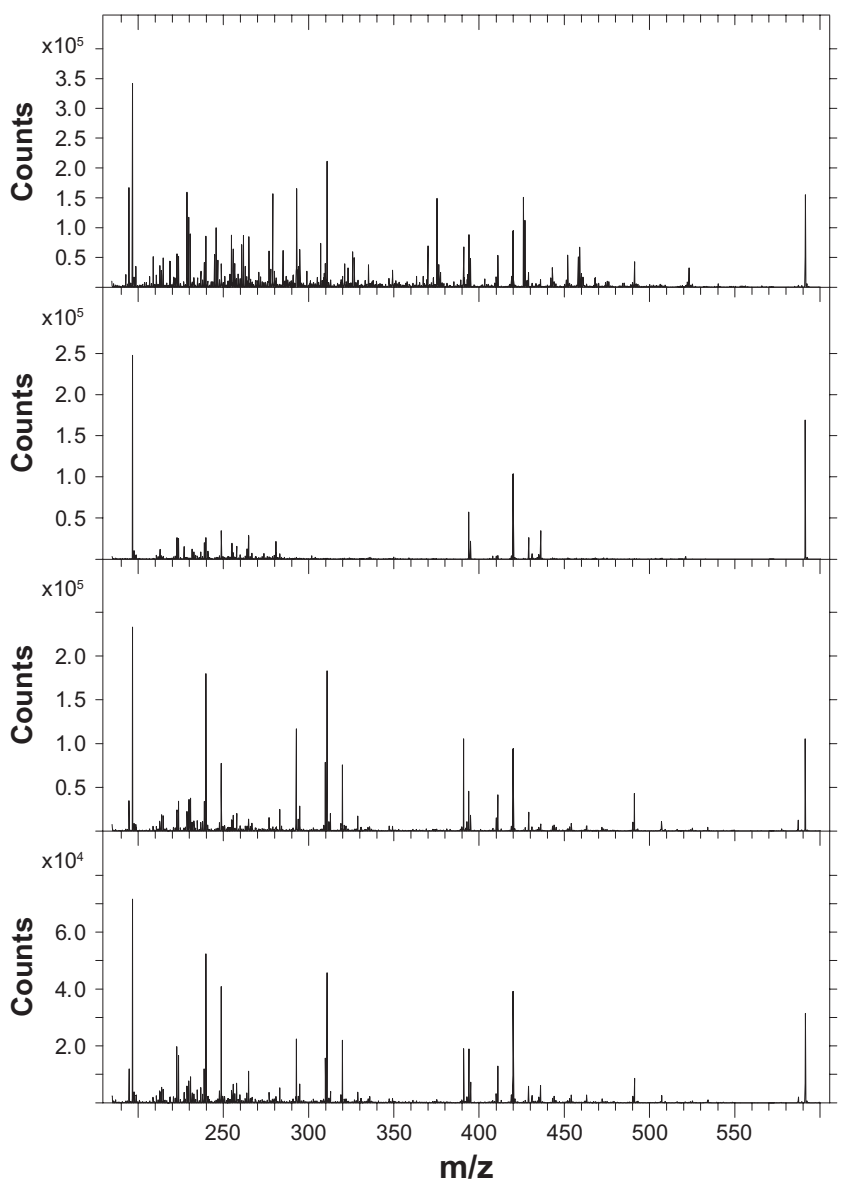

Figure S2 Negative secondary ion mass spectra from (A) cysteamine, nonwashed gold surface, (B) flat gold surface, (C) nanostructured gold surface, and (D) scratched area on nanostructured surface. 


\section{$\Delta \mathrm{F}(\mathrm{Hz})$}

$\Delta \mathrm{D}$

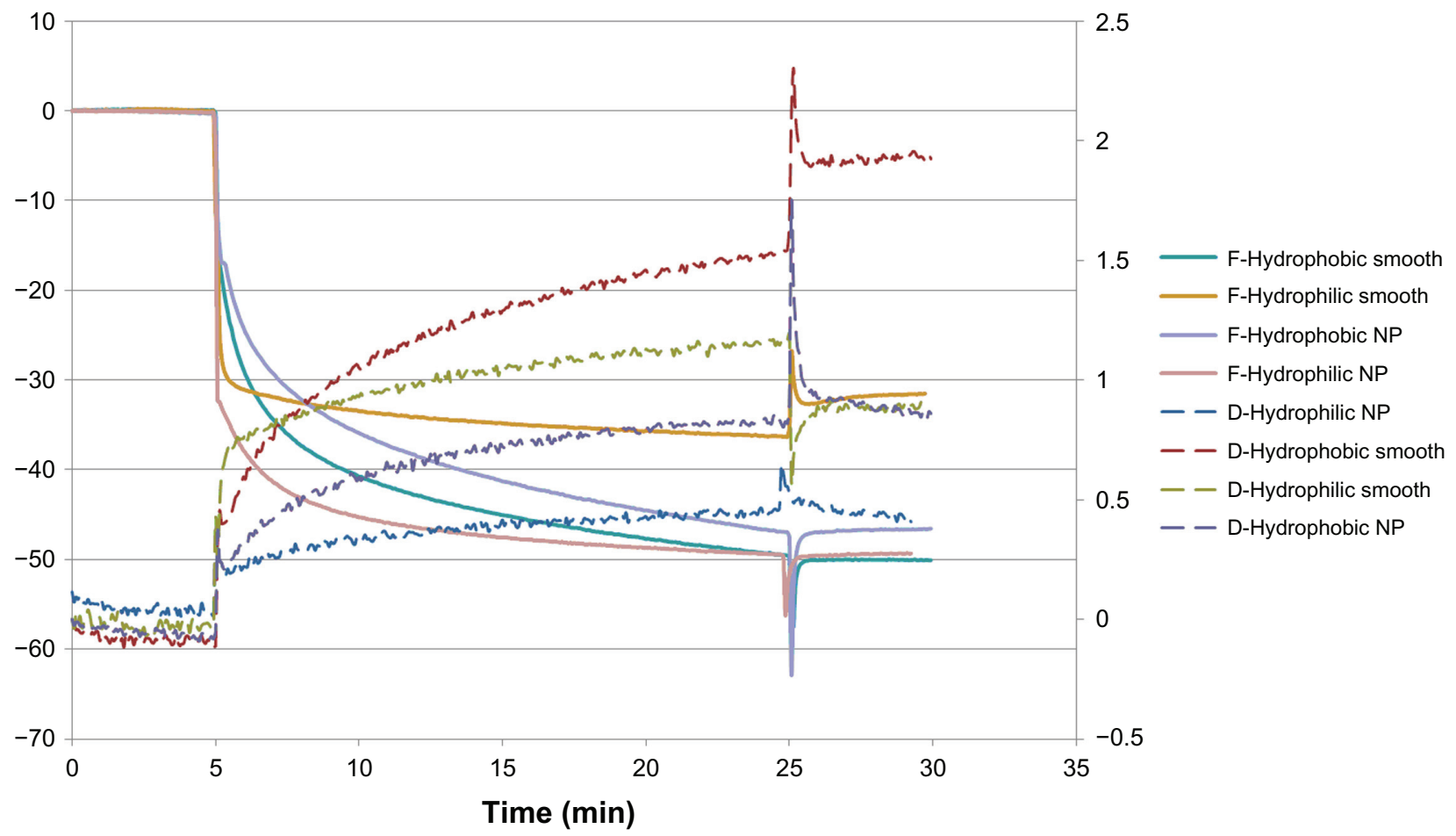

Figure S3 Representative QCM-D graph showing $\Delta \mathrm{F}$ and $\Delta \mathrm{D}$ for the adsorption of human $\operatorname{lgG}(\mathrm{I} 00 \mu \mathrm{g} / \mathrm{mL})$ for 20 minutes on hydrophilic and hydrophobic smooth and nanostructured gold surfaces. After 5 minutes of baseline with carrier buffer, lgG was introduced. After 20 minutes of adsorption of the protein, a 5 -minute rinse with carrier buffer was performed. Note the $\Delta \mathrm{D}$ when both nanostructured and smooth surfaces are hydrophobized, interpreted here as a higher degree of denaturation of the adsorbed protein.

Abbreviations: $\Delta \mathrm{F}$, change in resonance frequency; $\Delta \mathrm{D}$, change in dissipation; IgG, immunoglobulin G; NP, nanoparticle; QCM-D, quartz crystal microbalance with dissipation monitoring.

\section{Publish your work in this journal}

The International Journal of Nanomedicine is an international, peerreviewed journal focusing on the application of nanotechnology in diagnostics, therapeutics, and drug delivery systems throughout the biomedical field. This journal is indexed on PubMed Central, MedLine, CAS, SciSearch $\AA$, Current Contents ${ }^{\circledR} /$ Clinical Medicine,
Journal Citation Reports/Science Edition, EMBase, Scopus and the Elsevier Bibliographic databases. The manuscript management system is completely online and includes a very quick and fair peer-review system, which is all easy to use. Visit http://www.dovepress.com/ testimonials.php to read real quotes from published authors. 